\section{HISTOPATHOLOGICAL SPECTRUM OF UROTHELIAL LESIONS: AN OBSERVATIONAL STUDY}

KEY WORDS: Urothelial carcinoma, Squamous cell carcinoma, Papilloma, Cystoscopic Bladder Biopsy, Transurethral Resection of the bladder Tumour (TURBT)

\section{Dr. Nishat Ahmad* Dr. Saurabh Banerjee} Dr. A K. Srivastava
Junior Resident, Department of Pathology, Rajendra Institute of Medical Sciences, Ranchi *Corresponding Author

Tutor, Department of Pathology, Rajendra Institute of Medical Sciences, Ranchi

Professor, Department of Pathology, Rajendra Institute of Medical Sciences, Ranchi

BACKGROUND: Urinary bladder cancer is second most common cancer after prostate cancer in the genitourinary system. Urothelial Carcinoma is the commonest tumour type accounting for $90 \%$ of all primary tumours of the bladder Histopathological analysis of cystoscopic bladder biopsy and Transurethral resection of the bladder tumour (TURBT) material are the mainstay for cancer diagnosis. This study was aimed to determine the frequency of different types of neoplastic lesions of the urinary bladder and to determine the grade and stage of urothelial tumours. MATERIAL METHOD: The study was carried out in the Department of Pathology, Rajendra Institute of Medical Sciences (RIMS), Ranchi from January 2018 to June 2020 and included 30 cases of cystoscopic biopsies and TURBT specimens. RESULTS: Out of 30 cases of neoplastic lesions, majority were of high grade papillary urothelial carcinoma $(n=14,46.67 \%)$ followed by low grade papillary urothelial carcinoma $(n=9,30 \%), 3$ cases $(10 \%)$ were of PUNLMP, 2 cases $(6.66 \%)$ of papilloma and $l(3.33 \%)$ case each of moderately differentiated squamous cell carcinoma and extra nodal NHL. The most common age group was 41-50 years and 51-60 years with 9 (30\%) cases each. Muscle invasion was seen only in high grade papillary urothelial carcinomas. CONCLUSION: High-grade urothelial carcinomas with lamina propria and muscle invasion are the most common neoplastic lesion of urinary bladder with significant morbidity and mortality. Muscle invasion and grading, as per TNM staging, are valuable prognostic factors.

\section{INTRODUCTION}

Urinary bladder cancer is the ninth most common cancer worldwide and second most common malignancy of genitourinary tract after prostate cancer in male. As per Indian Cancer Registry data, it accounts for $3.9 \%$ of all cancers. ${ }^{[1]}$ Lesions of urinary bladder can be both non neoplastic and neoplastic, and are more disabling than lethal. $^{[2]}$

Cystitis, malakoplakia, urachal lesions and tuberculosis are the common non neoplastic lesions. ${ }^{[3]}$

Neoplastic lesions include both benign and malignant tumours with latter being more common and responsible for significant morbidity and mortality throughout the world. ${ }^{[4]}$ Majority of urinary tract tumours are of epithelial origin. ${ }^{[5]}$ Urothelial carcinoma is the most common tumour, constituting $90 \%$ of all primary tumours of urinary bladder. ${ }^{[6]}$ (Fig. 1). Renal pelvis, ureters and urethra are other common sites of urothelial carcinoma. ${ }^{[7]}$

The incidence of carcinoma of the bladder is higher in men $(6 \%)$ than in women $(2 \%)$ and about $80 \%$ of patients are between 50 and 80 years of age. ${ }^{[4]}$ It is more common in developed than in developing nations and in urban dwellers than in rural.

There is well established association between evolution of bladder cancer and some of the etiological factors. It can be either environmental or genetic. The environmental risk factors includes cigarette smoking, occupational carcinogens from chemical industry, schistosoma hematobium infection in endemic areas, use of artificial sweeteners, patients on long term use of cyclophosphamide and analgesics and patients receiving radiation therapy for genital cancers..$^{[2,8,9]}$

Among genetic factors, TP53, RB, PTEN pathways mutations are most commonly associated with invasive carcinoma and the combined mutations of these three pathways leads to bad prognosis. ${ }^{[10]}$ Other genetic factors such as null GSTM-
l(Glutathione-S transferase) and slow NAT-2(N- acetyl transferase) polymorphism also increases the risk of bladder cancer. First degree relatives are at about twice increased risk of developing urothelial cancer than the normal population. The neoplastic lesions of the bladder pose biologic, clinical, diagnostic and therapeutic challenges to both urologist and pathologist, as they represent a heterogeneous group of tumours with different subtypes and behavioural patterns. ${ }^{[2,1]}$

Cystoscopy is useful in localizing bladder tumours and to take biopsies of the suspected lesions. ${ }^{[12]}$ Cystoscopic bladder biopsy is a gold standard for diagnosis and prognostic assessment of these patients. Transurethral resection of the bladder tumour (TURBT), on the other hand, is a therapeutic procedure that allows assessment of the degree of differentiation and depth of tumour invasion, useful for elaboration of diagnosis and prognosis. ${ }^{[4]}$

The present study was conducted to describe the various histopathological spectrum of urinary bladder neoplasms in TURBT and cystoscopic biopsies and to determine the grade of urothelial tumours so as to prevent mortality and morbidity associated with it.

\section{MATERIAL AND METHODS}

The study was carried out in the Department of Pathology, Rajendra Institute of Medical Sciences (RIMS), Ranchi from January 2018 to June 2020. It included 30 cases of cystoscopic biopsies and TURBT specimens sent to the Histology section. The specimens were received in 10\% formalin. Gross examination of the tissue was done and findings were noted. The whole tissue was then processed as per standard procedure. Multiple sections of 3-5 microns thickness were obtained from the paraffin block and stained with haematoxylin and eosin. Histopathological examination was carried out and the lesions were classified into various lesions on light microscopy. Autolysed tissue and inadequate specimen were excluded from the study. The bladder lesions were studied according to WHO/ISUP (2004) classification. (Table 1) 
Table 1-Histologic features used to classify urothelial papillary lesions according to the scheme proposed by the WHO/ISUP (2004)

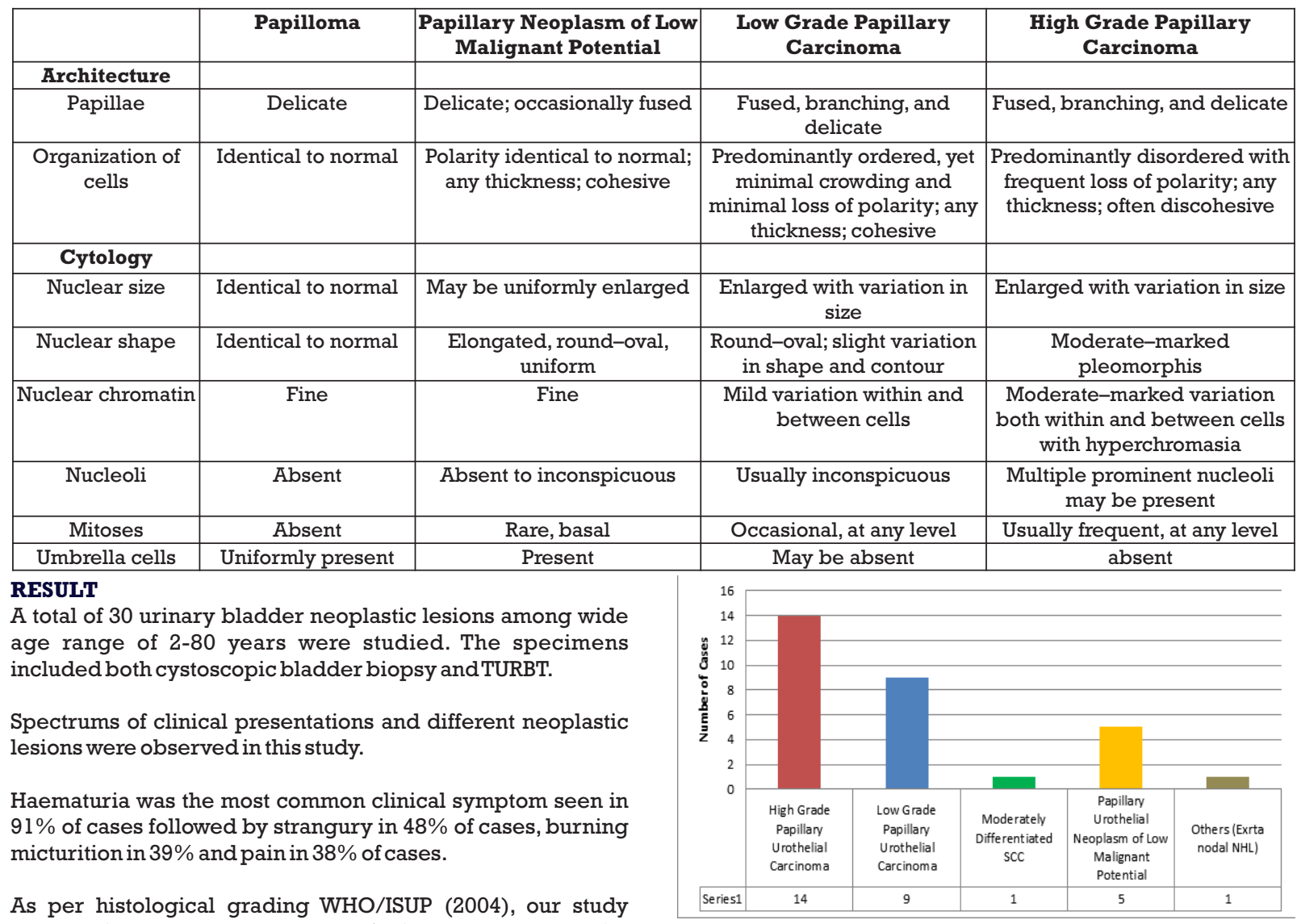
showed increased prevalence of high grade urothelial carcinoma (Fig.2, Fig.3), followed by low grade urothelial carcinoma and papillary urothelial neoplasm of low malignant potential (PUNLMP) accounting for $46.67 \%$ $(\mathrm{N}=14), 30 \%,(\mathrm{~N}=9)$ and $16.7 \%(\mathrm{~N}=3)$ respectively. (Table 2$)$

Table 2: Distribution of Cases according to microscopic Diagnosis

\begin{tabular}{|c|c|c|}
\hline MICROSCOPIC DIAGNOSIS & $\begin{array}{c}\text { No of } \\
\text { Cases }\end{array}$ & Percentage (\%) \\
\hline $\begin{array}{c}\text { High Grade Papillary Urothelial } \\
\text { Carcinoma }\end{array}$ & 14 & $46.67 \%$ \\
\hline $\begin{array}{c}\text { Low Grade Papillary Urothelial } \\
\text { Carcinoma }\end{array}$ & 9 & $30.0 \%$ \\
\hline $\begin{array}{c}\text { Papillary Urothelial Neoplasm of } \\
\text { Low Malignant Potential }\end{array}$ & 3 & $10.0 \%$ \\
\hline Papilloma & 2 & $6.66 \%$ \\
\hline Moderately Differentiated SCC & 1 & $3.33 \%$ \\
\hline Others (Extra nodal NHL) & 1 & $3.33 \%$ \\
\hline Total & $\mathbf{3 0}$ & $\mathbf{1 0 0 . 0 0 \%}$ \\
\hline
\end{tabular}

According to cystoscopic findings, 23 (76.66\%) patients had papillary mass, $6(20 \%)$ patients had solid mass and $1(3.33 \%)$ patient each showed diffuse thickening of the bladder wall and fungating mass.

The most common microscopic diagnosis was high-grade papillary urothelial carcinoma in 14 cases $(46.67 \%)$ while 1 case $(3.33 \%)$ was of extra nodal Non Hodgkin's lymphoma of urinary bladder. Other microscopic diagnosis were lowgrade papillary urothelial carcinoma in $9(30 \%)$ samples, Papillary urothelial neoplasm of low malignant potential in 5 $(16.67 \%)$ samples while only one sample $(3.33 \%)$ showed moderately differentiated squamous cell carcinoma (Fig.4, Fig.5).(Bar Diagram)

Bar Chart showing distribution of cases according to microscopic diagnosis

Most common age group was $41-60$ years (60\% patients) followed by $61-70$ years (23.33\% patients). Among the study population, 24 cases $(80 \%)$ were males and 6 cases $(20 \%)$ females with male to female ratio of $4: 1$. Thus male preponderance was observed among Urothelial neoplastic lesion. (Table 3)

Table 3: Showing Age wise and gender wise distribution of Urothelial Carcinoma cases

\begin{tabular}{|c|c|c|c|c|}
\hline \multirow{2}{*}{$\begin{array}{c}\text { Age Group } \\
\text { (yrs) }\end{array}$} & \multicolumn{2}{|c|}{ Neoplastic Lesion } & \multirow{2}{*}{$\begin{array}{c}\text { Total no of } \\
\text { cases }\end{array}$} & $\begin{array}{c}\text { Percentag } \\
\text { e (\%) }\end{array}$ \\
\cline { 2 - 3 } & Male & Female & 2 & $6.67 \%$ \\
\hline$<20$ & 2 & 0 & 2 & $6.67 \%$ \\
\hline $21-30$ & 2 & 0 & 0 & $0.00 \%$ \\
\hline $31-40$ & 0 & 0 & 9 & $30.00 \%$ \\
\hline $41-50$ & 7 & 2 & 9 & $30.00 \%$ \\
\hline $51-60$ & 7 & 2 & 7 & $23.33 \%$ \\
\hline $61-70$ & 5 & 2 & 1 & $3.33 \%$ \\
\hline$>70$ & 1 & 0 & 30 & $100.00 \%$ \\
\hline Total & 24 & 6 & & \\
\hline
\end{tabular}

As per TNM staging used, 1 case (3.33\%) was in pTis stage, 9 cases $(30 \%)$ were in pTl stage and 7 cases $(23.33 \%)$ were in pT2 stage. Muscle invasion was seen in 7 (23.33\%) cases of high grade papillary urothelial carcinoma. (Table 4)

Table 4: Histological staging of urothelial neoplasm as perTNM staging

\begin{tabular}{|c|c|c|c|}
\hline S .No & Staging & No .of cases & Percentage \\
\hline 1. & pTis & 1 & $5.88 \%$ \\
\hline 2. & pT1 & 9 & $52.94 \%$ \\
\hline 3. & pT2 & 7 & $41.18 \%$ \\
\hline & Total & 17 & \\
\hline
\end{tabular}




\section{DISCUSSION}

The urinary bladder and renal pelvis are more common sites for urothelial carcinomas, than the ureters and urethra. ${ }^{[13]}$ P.Bozzoni in 1805 described the first cystoscope consisting of a metal tube which on the extra-vesicle end applied a spark plug through which the vesicle field was illuminated. The first bladder biopsy forceps was independently described by Young and Manon in 1929 by which it was possible to extract portions of tumour tissue. ${ }^{[15]}$ Cystoscopy and TURBT are commonly practiced therapeutic and diagnostic procedures that allow urologists to completely visualize bladder mucosa followed by sampling of the tissue for the histopathological examination.

Thirty cases of urinary bladder lesions were included in our study. The male to female ratio from various studies highlight the association between bladder neoplasms and increased male susceptibility. Present study also had male preponderance with M: F ratio of 4:1. However, the range of this ratio is very wide as observed in various studies ranging from least being observed is 2.29:1 in study by Shah PY et al. ${ }^{[16]}$ to highest observed ratio of 5.25:1 in study by Srikoustubah et al. ${ }^{[17]}$ Smoking had a predominant role in development of bladder cancer in males along with other factors such as occupational carcinogens like aniline dyes (particularly benzidine and $\beta$-naphthylamine), auramines, phenacetin and cyclophosphamide. Schistosoma haematobium is also thought to be pathogenetically related to urothelial (and squamous cell) carcinoma of bladder Incidence among females could be explained by use of smokeless tobacco in the forms like gutkha, paan, khaini, tobacco or surti. These contain many procarcinogenic agents like nicotine, saccharin, sugar coated fennel and heavy metals like silver. ${ }^{[18]}$

High grade urothelial neoplasm was the predominant type with a significant proportion of lesions seen in males. It included $3(10 \%)$ cases of papillary urothelial neoplasm of low malignant potential, $9(30 \%)$ were low-grade noninvasive urothelial carcinoma and 14 (46.67\%) were high grade urothelial carcinoma.

Out of all urothelial neoplasms samples in the present study, 9 (30\%) were non-invasive papillary carcinoma, 7 (23.33\%) were showing invasion into lamina propria (superficially invasive bladder carcinoma) whereas 7 (23.33\%) were showing invasion into muscularis propria (muscle invasive bladder cancer). Other authors like Laishram et al. ${ }^{[1]}$ showed $53.85 \%$ of non-invasive papillary carcinoma, $15.38 \%$ of superficially invasive bladder carcinoma and $30.77 \%$ of muscle invasive bladder carcinoma in their study. The risk of recurrence and disease progression does not solely depend on growth pattern and histological grade of tumour. It also depends on various other factors such as size, multi-focality, time of recurrence, prior intra-vesicle therapy. Much of the controversies regarding grading are now solved by use of ancillary techniques like Immunohistochemistry (IHC) or Molecular assay. ${ }^{[19]}$

\section{CONCLUSION}

Urinary bladder lesions are frequently encountered by surgical pathologists. Both benign and malignant lesions are documented, latter being more common. It is more common in elderly people with male predilection and often associated with smoking. However, there is increasing incidence in the female population in the recent years which might be due to increased exposure to environmental and occupational carcinogens along with exposure to smokeless tobacco.

Identifying the extent of invasion of neoplasm by microscopic examination is important. Invasion of muscularis mucosa and muscularis propria has to be differentiated carefully as the prognostic and therapeutic aspects are entirely different in both of them. IHC is helpful in cases of diagnostic dilemma. Awareness regarding the various histological features of these lesions, their neoplastic potential, risk of recurrence and possible pitfalls helps in accurate diagnosis.

\section{FIGURES}

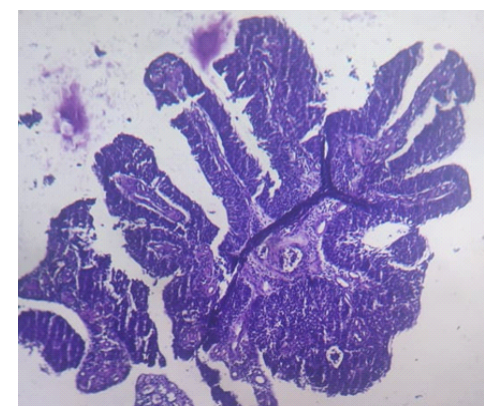

Fig 1: Urothelial Carcinoma (H \& E 20X)

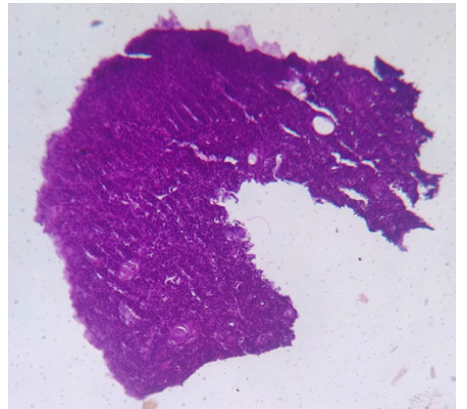

Fig 2: High Grade Urothelial Carcinoma (H\&E 10X)

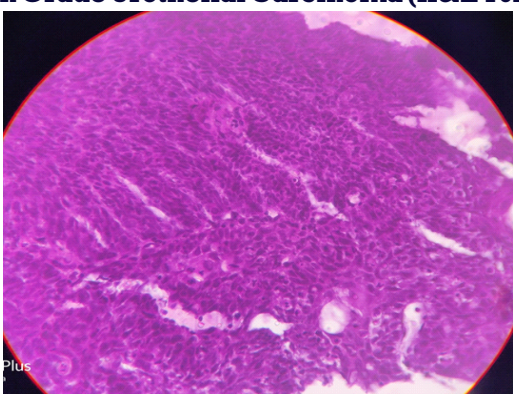

Fig 3: High Grade Urothelial Carcinoma (H\&E 40X)

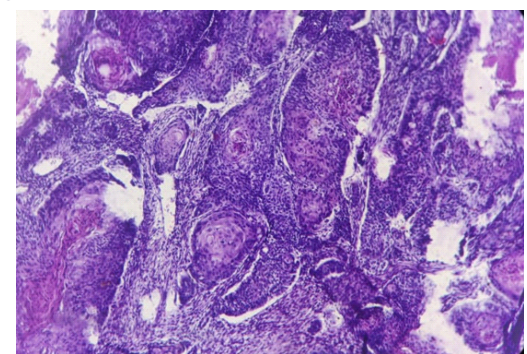

Fig 4: Moderately differentiated Squamous Cell Carcinoma.(H \& E 20X)

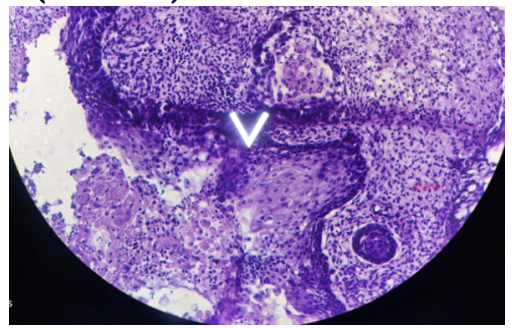

Fig 5 : Moderately differentiated Squamous Cell Carcinoma.(H \& E 40X)

\section{REFERENCES}

1. Laishram RS, Kipgen P, Laishram S, Khuraijam S, Sharma DC. Urothelial Tumors of the Urinary Bladder in Manipur: A Histopathological Perspective. Asia Pacific JCancer Prev,2012; 13:2477-2479. 
2. Epstein JI, Lotan TL. The Lower Urinary Tract and Male Genital System. In: KumarV, Abbas AK, Aster JC, editors. Robbins and Cotran Pathologic Basis of Diseases.9thed.Faridabad:Elsevier;2014.961-9.

3. Goyal VK, Vyas SP, Kothari DC. Spectrum of Lesions in Urinary Bladder Biopsies :Histopathological Study. Int JDent Med Res. 2015;1(6):42-6.

4. Pudasaini S, Subedi N, Prasad KBR, Rauniyar SK, Josi BR,Bhomi KK Cystoscopic bladder biopsies: A histopathological study. Nepal Med Coll J. 2014;6(1):9-12.

5. Shruthi.HP, Rangaswamy.R. Spectrum of Lesions in Urinary Bladder Biopsies-A Histopathological Study.IJHSR.2015 May;5(5):144-52

6. Kumar MU, Yelikar BR. Spectrum of Lesions in Cystoscopic Bladder Biopsies-A Histopathological study. Al ameen J Med Sci 2012:5:132-6.

7. Aparna C, Thumma RR, Devi CP, Vanapalli SVRLJ, Mounika TDN. Histopathological Spectrum of Urothelial lesions- Experience of A Single Tertiary Care Institute. IJCMR. 2016;3(6):1731-3

8. Kumar MU, Yelikar BR. Spectrum of Lesions in Cystoscopic Bladder Biopsies-A Histopathological Study. Al Ameen J Med Sci. 2012;5(2):132-6.

9. 7. Matalka I, Bani HK, Shota A, Bani HO, Bani HI. Transitional cell carcinoma of the urinary bladder: a clinicopathological study. Singapore Med J.2008;49(10):790-4.

10. Wood DP. Tumors of Bladder. In:WeinJA, Kavoussi RL, PartinWA, Peters CA editors. Campbell-Walsh Urology.11thed. China: Elsevier; 2016. 2184 204.

11. Hussain N, Shumo A, Mekki S et al. A clinicopathological study of urinary bladder neoplasms in patients at three centers in Khartoum, Sudan. Sudan Journal of Medical Science 2009;4:249-55

12. Felix AS, Soliman AS, Khalad H, Zaqhloul MS, Banerjee M, El-Baradie Met al. The changing patterns of bladder cancer in Egypt over the past 26 years. Cancer Causes Control.2008 May;19(4):421-9.

13. Kazi JI et al. Spectrum of pathological lesions in Cystoscopic Bladder Biopsies - A clinicopathologic study. J Coll Physicians Surg Pak. 2002;12:744-7.

14. Golding, J. (2000), A Dictionary of the History of Medicine. By Anton Sebastian.NewYork/London:Parthenon, 1999, 781p.

15. Oscar Flores-Carreras, María Isabel González Ruiz and Claudia Josefina Martínez Espinoza. The Importance of Urethrocystoscopy and Bladder Biopsy in Gynecologic Patients in Basic Gynecology - Prof. Atef Darwish (Ed.), 2012;978-953-51-0166-6.

16. Shah PY, Nanavati M, Patel RG, Goswami HM. Spectrum of lesions in urinary bladder- A histopathological study. Int J Cur Res Rev. 2016;8(4):19-24.

17. . Srikousthubha, Sukesh, Raghuveer CV, Hingle S. Profile of Lesions in Cystoscopic Bladder Biopsies: A Histopathological Study. J Clin Diagn Res.2013 Aug;7(8):1609-12.

18. Chinnaswamy R, Krishnamoorthy S, Joseph L, kumaresan N, Ramanan V. Clinico-pathological Study of Bladder Cancer in a Tertiary Care Centre of South India and Impact of Age, Gender, and Tobacco in Causing Bladder Cancer:A Single Centre Experience. Int J Sci Stud. 2016;3(10):72-7.

19. Humphrey PA, Moch H, Cubilla AL, Ulbright TM, Reuter VE. The 2016 WHO Classification of tumours of the Urinary System and Male Genital OrgansPart B:Prostate and Bladder Tumours. Eur Urol.2016 July;70(1):110-5 